\title{
SEISMIC PERFORMANCE EVALUATION OF BOX-SHAPED WALL STRUCTURES BUILT WITH THICK EARTHEN WALLS
}

\author{
HAJIME YOKOUCHI $^{1 *}$, YOSHIMITSU OHASHI ${ }^{2}$ \\ ${ }^{1}$ Architecture Course, School of Science and Technology \\ Kokushikan University \\ 4-28-1, Setagaya, Setagaya-ku, Tokyo, Japan \\ e-mail: yokouchi@kokushikan.ac.jp, web page: https://kokushikan-arch.net/yokouchi-lab/ \\ ${ }^{2}$ Department of Architecture, Faculty of Engineering \\ Tokyo City University \\ 1-28-1, Tamazutsumi, Setagaya-ku, Tokyo, Japan \\ e-mail: ohashi-y@tcu.ac.jp
}

Keywords: Traditional Japanese Structure, Mud Wall, Loading Test, Response Spectrum Method

\begin{abstract}
A "dozo-dukuri" is a type of traditional Japanese building characterized by a box-shaped wall structure built with thick earthen walls. This structure is referred to as the dozo structure in this paper. However, very little information on the seismic performance of dozo structures have been provided in the literature. Therefore, we performed a horizontal loading test on full-scale walls produced based on survey results and specifications of earthen walls around the northern Kanto region to determine the walls' structural performance when receiving a horizontal force (e.g., an earthquake). As a case study, the seismic performance of an existing building was evaluated using the test results. The case study results indicate that if the maximum response deformation angle is equal to that in the calculation result or less, the possibility of a building collapse due to the assumed ground motion is low.
\end{abstract}

\section{INTRODUCTION}

Methods of mixing soil with organic fibers, such as straw, and fixing soil on a substrate knitted with bamboo or wood have been used for construction worldwide [1-7]. Earthen walls have also been used in Japan since a long time ago. A type of traditional Japanese building is the "dozo-dukuri," which is a box-shaped wall structure built with thick earthen walls. The structure is referred to herein as the dozo structure. Figure 1 shows examples of dozo structures, including "misegura," which are dozo townhouses intended to be multiuse shops or dwellings, and storehouses, called "dozo." The northern Kanto region and their surroundings form a distinctive historical townscape because these traditional Japanese buildings built from the end of the Edo Period to the early Showa Period (approximately 70-180 years ago) were constructed in rows and clusters. Dozo structures have earthen walls that are 200-300 mm thick at their outer circumference for protection against fire. Although originally used as warehouses, these structures came to be used as stores, parlors, and other kinds of buildings in modern times.

The traditional townscapes and dozo structures of the Kanto region were seriously damaged in the 2011 Tohoku Region Pacific Offshore earthquake [8,9]. The Kumamoto and Tottori 
earthquakes that occurred in 2016 also caused significant damage to the shear walls of the dozo structures, and their restoration is still ongoing. Damage to historical structures not only creates a safety hazard for people in and around them, but also strikes a blow to the vitality of a community. Therefore, their seismic performance must be understood, and measures for damage reduction must be taken. However, there is little information on the seismic performance of dozo structures. Therefore, we must create an evaluation method of the seismic performance of these traditional and existing houses and buildings.

This study performs a horizontal loading test on full-scale walls produced based on the specifications of the earthen walls around the northern Kanto region to determine the walls' structural performance when experiencing horizontal force (e.g., an earthquake). As a case study, the seismic performance of the existing building is then evaluated using the test results.

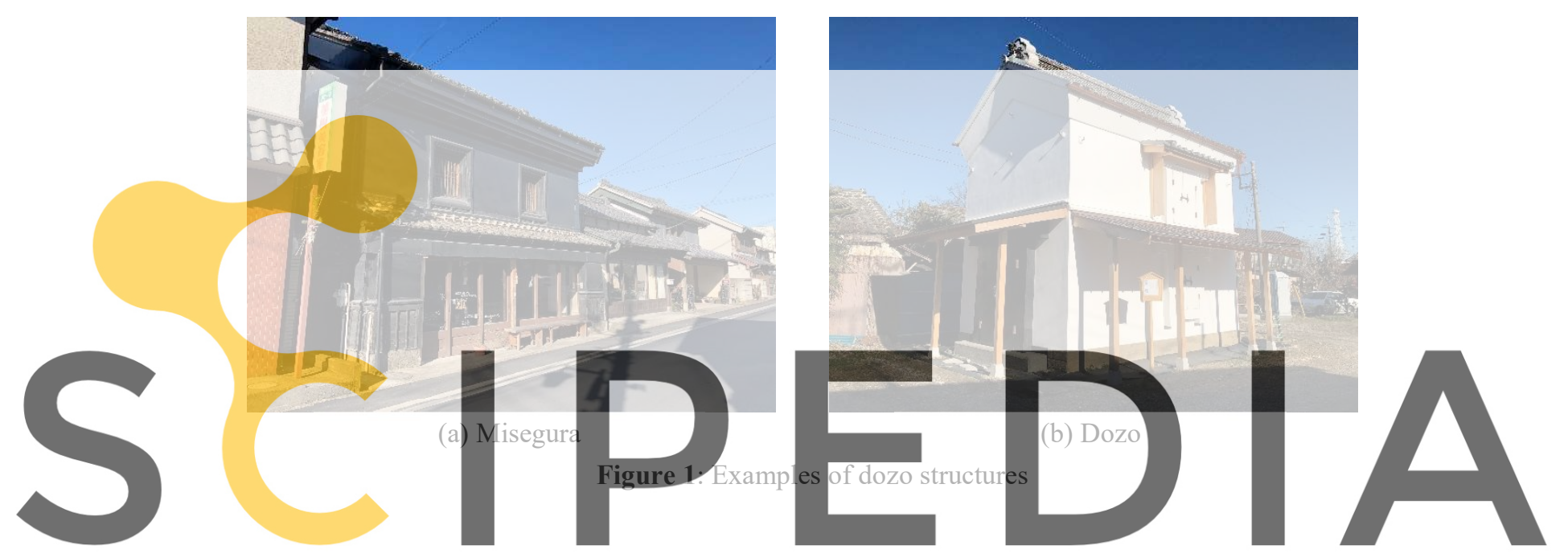

2 SPECIIFICATIONS OF THE EARTHEN WALLS USED IN DOZO STRUCTURES

Register for free at https//www.scipedia.com to download the version without the watermark Figure 2 shows a detailed vlew of the inner earthen wall after the sampling survey. Figure 3

depicts a detailed cross-sectional view around a pillar. Table 1 presents the specifications of the earthen walls around the northern Kanto region observed from the surveys. The following procedure was used to identify the details and processes of the walls. (1) We interviewed skilled technicians (carpenters and plasterers); (2) conduct a field survey to measure features such as the size and placement of the bamboo and penetrating tie beam inside the earthen wall from walls where the mud had peeled off; and (3) cut out the wall of a storehouse to be demolished.

Two types of mud, namely, rough wall mud and intermediate coating mud, were used in the earthen walls. The rough wall mud was clay mixed with straw that was approximately $50 \mathrm{~mm}$ long and kneaded with water. The intermediate coating mud was clay mixed with sand and fibrous straw that was approximately $20-30 \mathrm{~mm}$ long and kneaded with water.

Traditional Japanese wooden structures feature walls constructed with exposed timber pillars, but in dozo structures, thick earthen walls were used to cover the outside pillar. Therefore, the base layer bamboo was not split, and round bamboo was used. First, an inner horizontal bamboo was hung between the pillars on both sides in a frame, and a vertical bamboo was installed on the outside. An outer horizontal bamboo was placed into a sawblade-shaped bracket cut out of the pillar, such that the weight of the mud was transferred from the outer horizontal bamboo to 
the pillars. The bamboo intersections were tightly tied with a straw rope to produce a solid substrate.

In constructing parts of the wall, where the cross-section became smaller due to the timber frame, the rough wall, longitudinal rope, barrel roll, and straw rope were densely arranged to maintain mud integrity. Furthermore, when increasing the wall thickness, rough wall mud was used with intermediate coating mud thinly plastered to reinforce the fixing of the rough wall mud and smoothen the wall surface. Then, the walls were retouched, and the finishing materials were plastered.

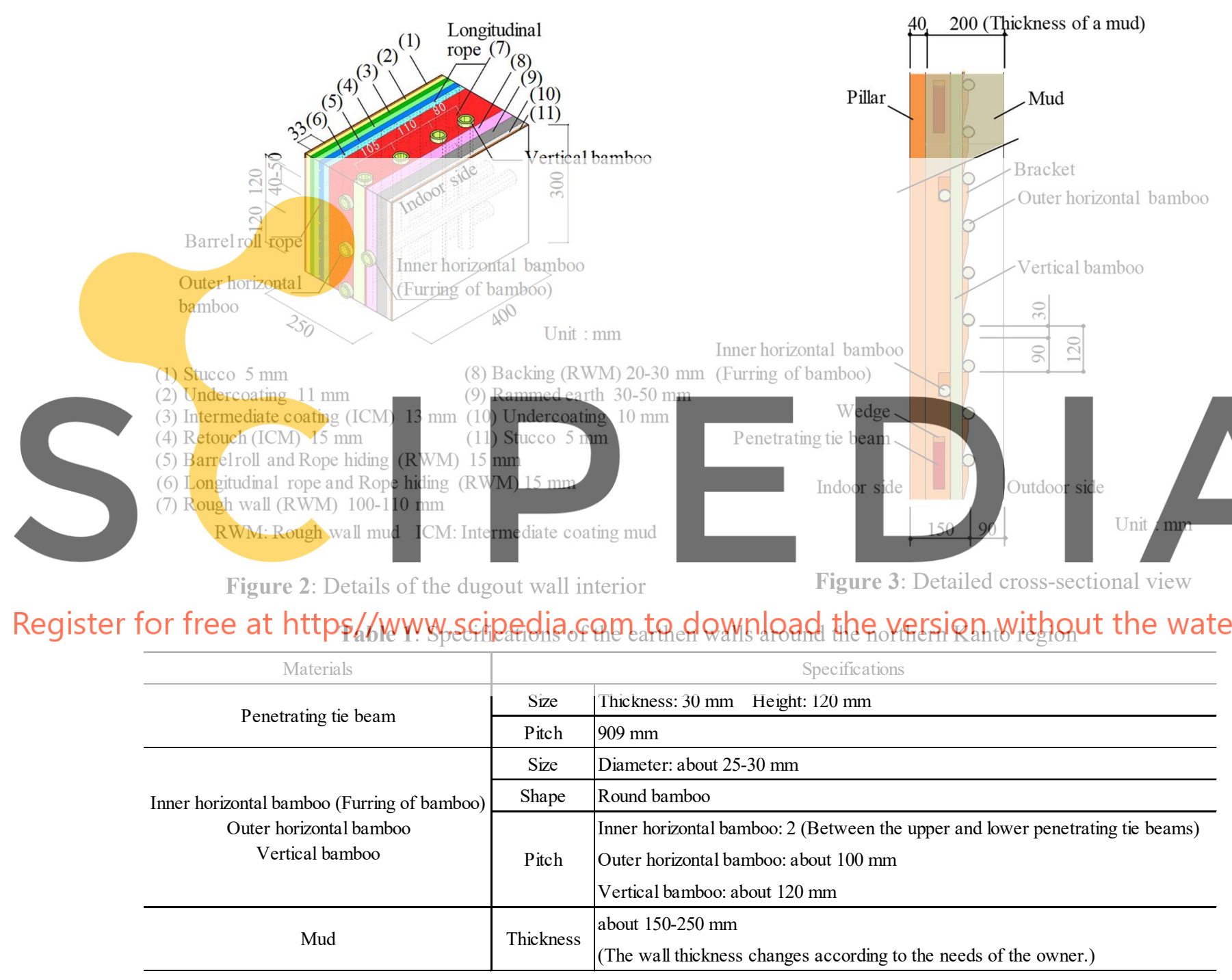

\section{STRUCTURAL PERFORMANCE EVALUATION OF THE EARTHEN WALLS}

\subsection{Specimen overview}

This research included the construction and load testing of two specimen types, as described in Figure 4. The Type A specimen, which was of the framework only, was used to confirm the 
effect of the penetrating tie beams. Meanwhile, the Type B specimen was used to clarify the strength, deformation performance, and damage state of the original earthen wall of a dozo

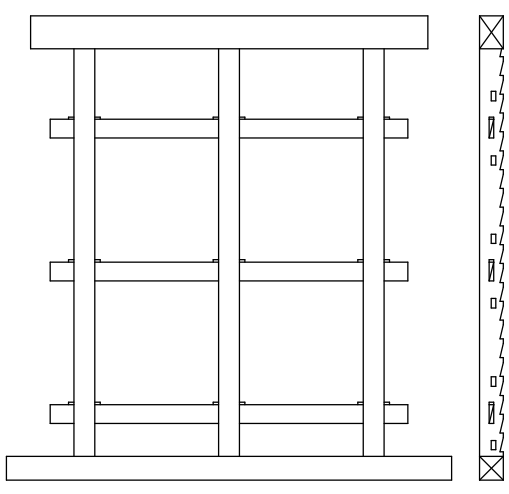

(a) Type A

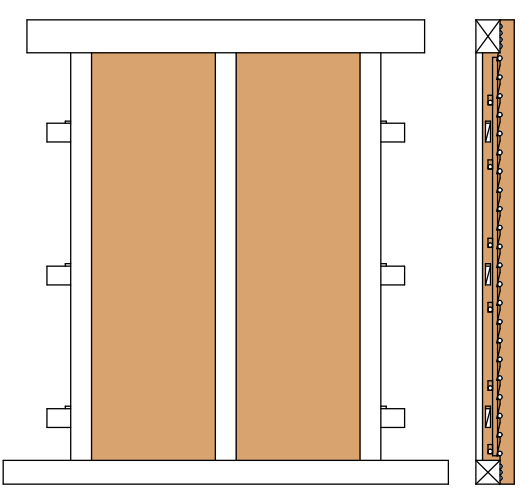

(b) Type B
西

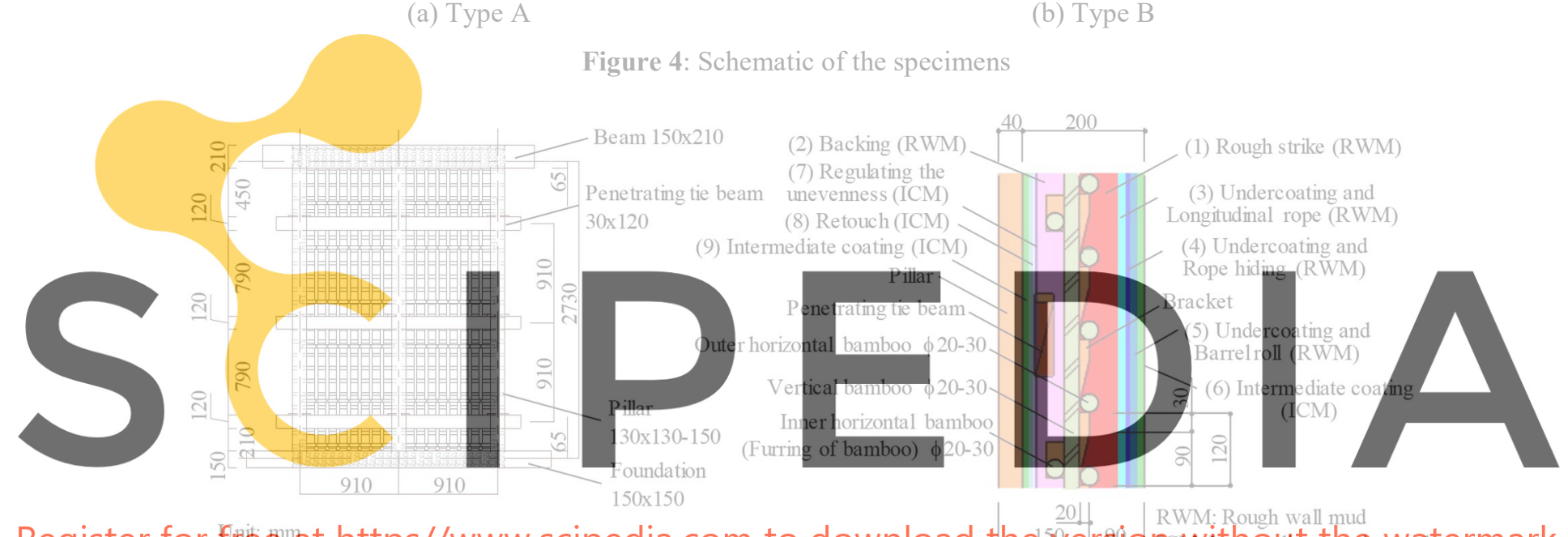

Register for freemat https//www.scipedia.com to download thespersionwwithoutate the watermark

Figure 5: Shapes and dimensions of the Type B specimen

Table 2: Outline of elements and specifications

\begin{tabular}{|c|c|c|c|}
\hline \multicolumn{3}{|c|}{ Elements } & Specifications \\
\hline \multirow{9}{*}{$\begin{array}{l}\text { Type A } \\
\text { Type B }\end{array}$} & \multirow[b]{2}{*}{ Pillar } & Material & Japanese cedar \\
\hline & & Size & $\begin{array}{c}\text { Width 130mm x Depth 130-150mm } \\
\text { (Bracket 20mm) }\end{array}$ \\
\hline & \multirow{2}{*}{ Foundation } & Material & White cedar \\
\hline & & Size & $150 \mathrm{~mm} \times 150 \mathrm{~mm}$ \\
\hline & \multirow{2}{*}{ Beam } & Material & White cedar \\
\hline & & Size & Width $150 \mathrm{~mm} \times$ Depth $210 \mathrm{~mm}$ \\
\hline & \multirow{2}{*}{ Penetrating tie beam } & Material & Japanese cedar \\
\hline & & Size & Width $30 \mathrm{~mm} \times$ Depth $120 \mathrm{~mm}$ \\
\hline & Wedge & Material & White cedar \\
\hline \multirow{4}{*}{ Type B } & Surface protection of penetrating tie beam & Material & Rush (Ryukyu) L=250mm \\
\hline & \multirow{2}{*}{ Bamboo } & Material & Long-jointed bamboo (Madake) \\
\hline & & Size & Diameter: $20-30 \mathrm{~mm}$ \\
\hline & Mud wall & Thickness & Plan: 200mm Product: $204 \mathrm{~mm}$ \\
\hline
\end{tabular}


structure. The Type B specimen was constructed based on the specifications clarified in the earlier survey, such as including bamboo fitting in the wall, production process, and preparation of the wall mud plaster (i.e., rough wall mud and intermediate coating mud).

Figure 5 shows the shapes and dimensions of the Type B specimen. Table 2 presents the materials and specifications used. The specimen shapes and dimensions and the materials used were basically the same (i.e., width: two $910 \mathrm{~mm}$ spans and height: $2730 \mathrm{~mm}$ ). The joint between the pillar and the horizontal frame was shaped such that the pillar end did not touch the horizontal frame, even in the case of a significant deformation. By doing so, we ignored the resistance caused by the pillar sinking into the horizontal frame; hence, we could observe only the wall panel performance.

Table 3 lists the composition of the rough wall mud and the intermediate coating mud used in the test specimens. Figure 6 illustrates the compression strength tests for the two types of mud performed according to the method developed by the Japanese Housing and Wood Technology Center [10]. Table 4 presents the compression strength test results. Figure 7 shows the stress-strain curves with an average of six samples.

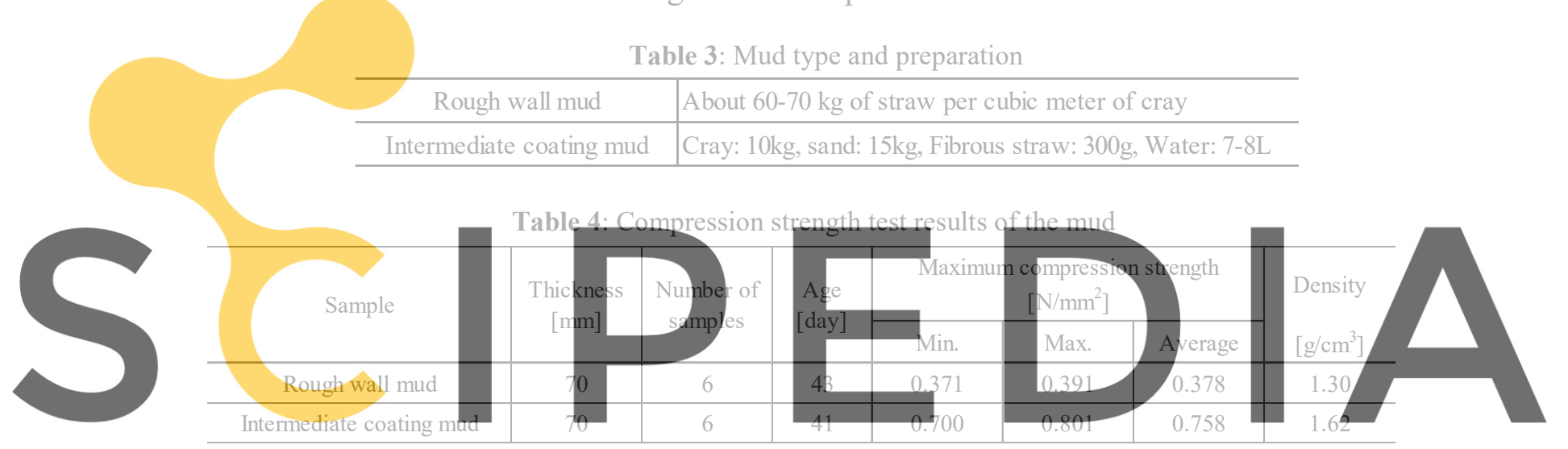

Register for free at https//www.scipedia.com to download the version without the watermark

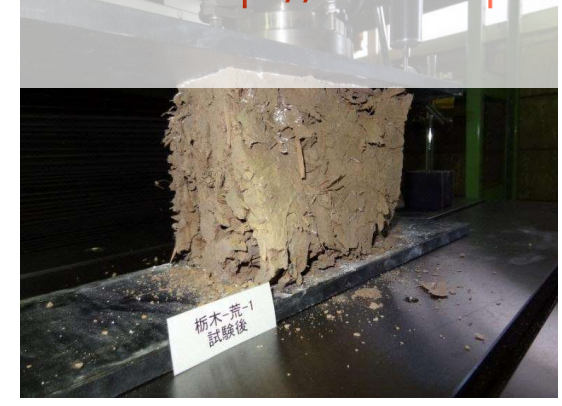

Figure 6: Situation of the material tests

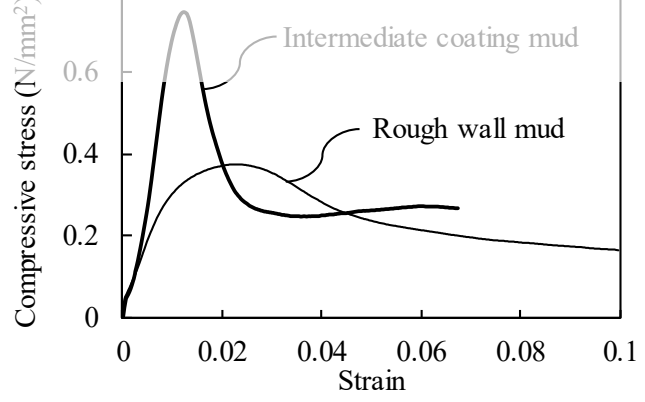

Figure 7: Stress-strain curves with an average of six samples

\subsection{Load-measuring method}

Measurement and loading were performed using the method in Figure 8. Positive and negative alternating loading by displacement control was performed. The loading schedule of gradually increasing the shear deformation angle to $1 / 600 \mathrm{rad}, 1 / 450 \mathrm{rad}, 1 / 300 \mathrm{rad}, 1 / 200 \mathrm{rad}$, $1 / 150 \mathrm{rad}, 1 / 100 \mathrm{rad}, 1 / 75 \mathrm{rad}, 1 / 60 \mathrm{rad}, 1 / 50 \mathrm{rad}, 1 / 40 \mathrm{rad}$, and 1/30 rad in three cycles was 
followed by one cycle of 1/20 rad loading. Finally, we applied loading (deformation angle: approximately $1 / 7 \mathrm{rad}$ ) to pull up to the allowable jack stroke.

The measurement items common to all the specimens were horizontal load, horizontal displacement of the beam and foundation, lifting displacement of pillar bases, and axial strain of the pillar top/base fixing bolts. In the Type B specimen, we regarded the crack occurrence and the main crack width when each controlled deformation was reached.

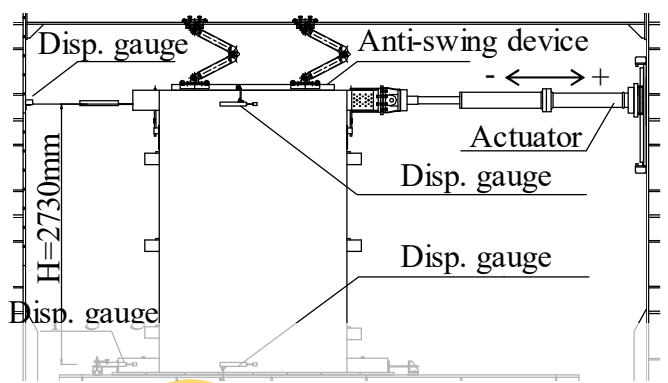

(a) Outdoor side

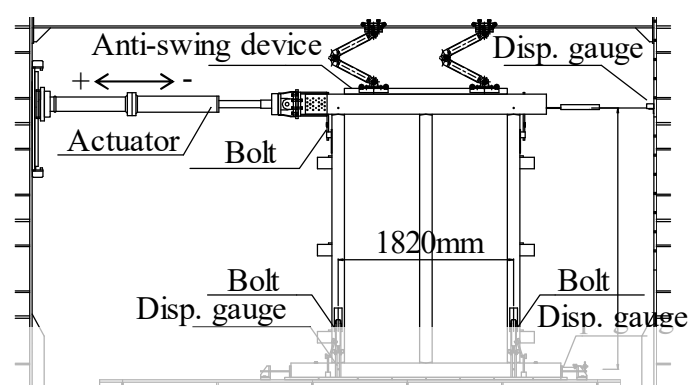

(b) Indoor side

Figure 8: Methods of measurement and loading

\subsection{Test results}

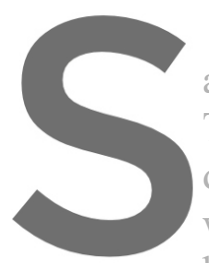

\section{Figure 9 displays th} angle of the type $A$ and Type A wall was significantly less than deformation increased, was confirmed even if by the penetrating tie beams sinking into the pillars
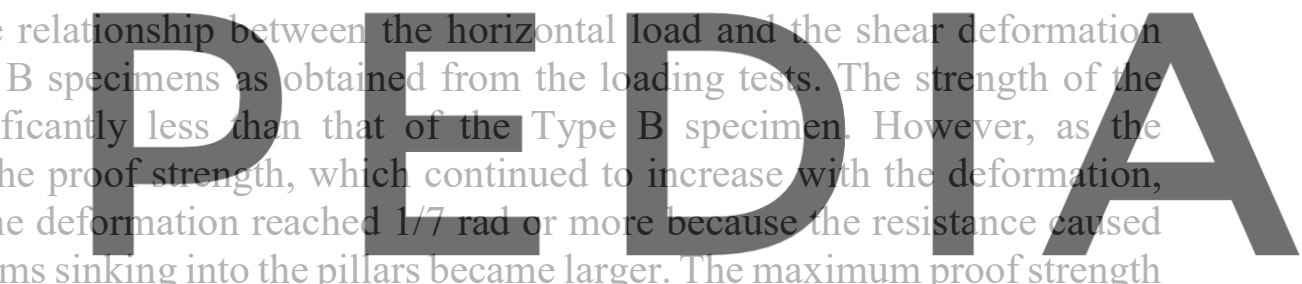

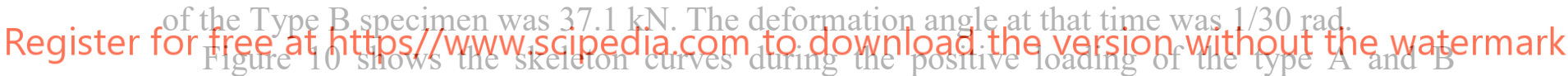

specimens and the restoring force of only the mud wall panel subtracting the Type A specimen from Type B at the same deformation. After the maximum proof strength was obtained, the resistance strength of the mud wall panel decreased; however, with Type A, the resistance strength of the penetrating tie beams increased with the horizontal deformation. We confirmed
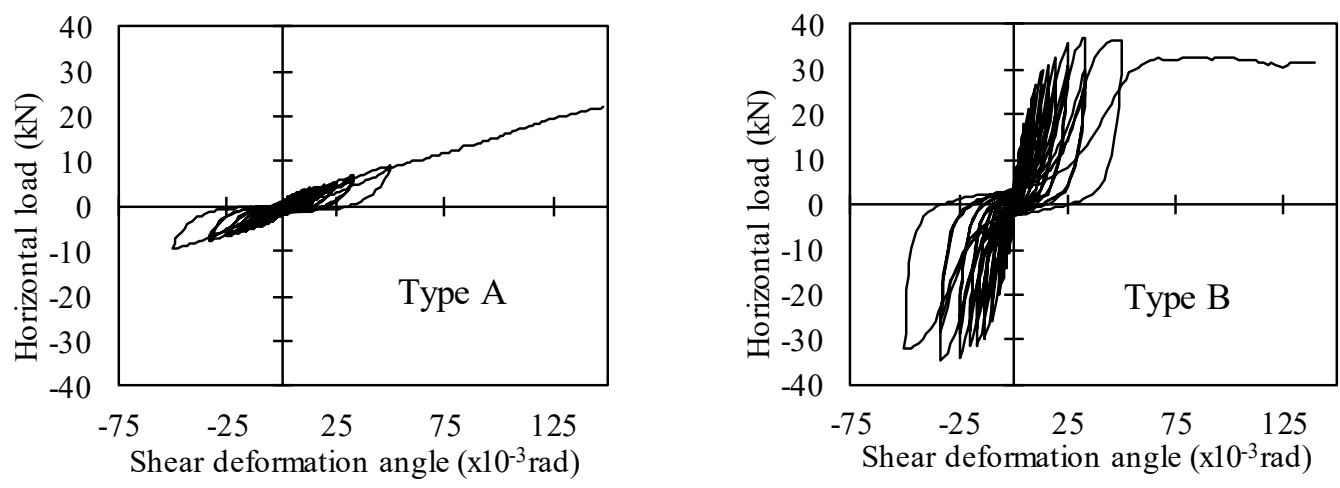

Figure 9: Relationship between the horizontal load and the shear deformation angle 
the toughness of the thick earthen walls by maintaining a proof strength of $84 \%$ or higher of the maximum up to the final deformation by balancing the mud wall panel resistance and the penetrating tie beam resistance.

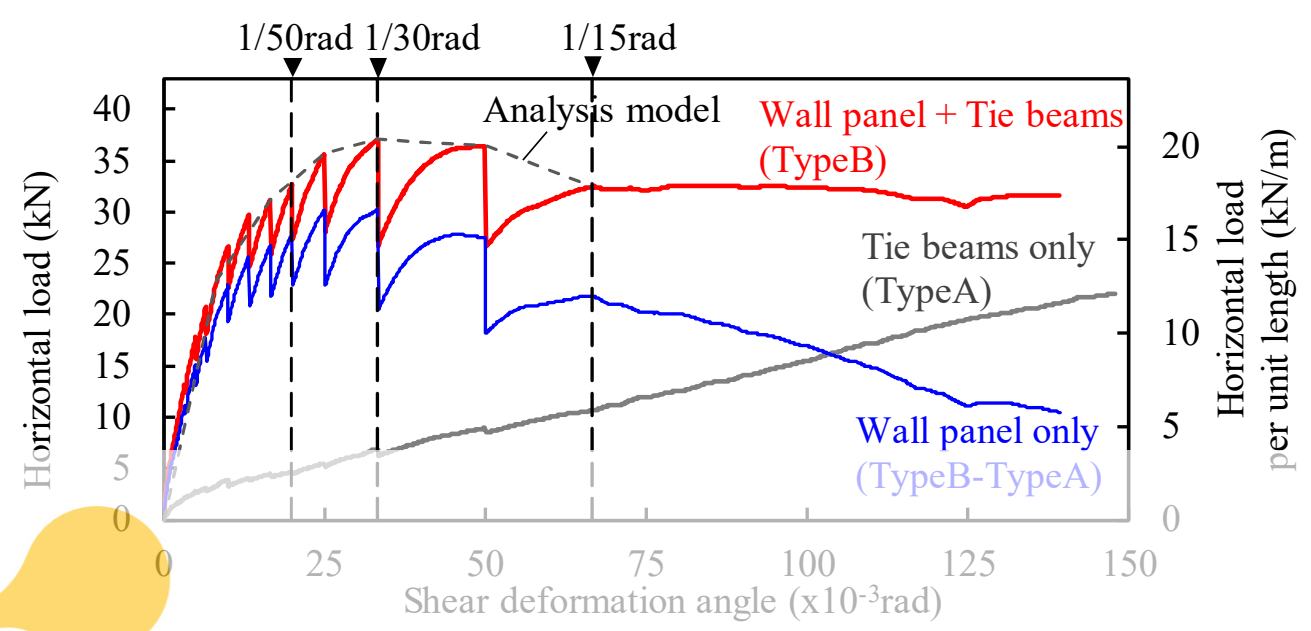

Figure 10: Skeleton curve comparison during positive loading
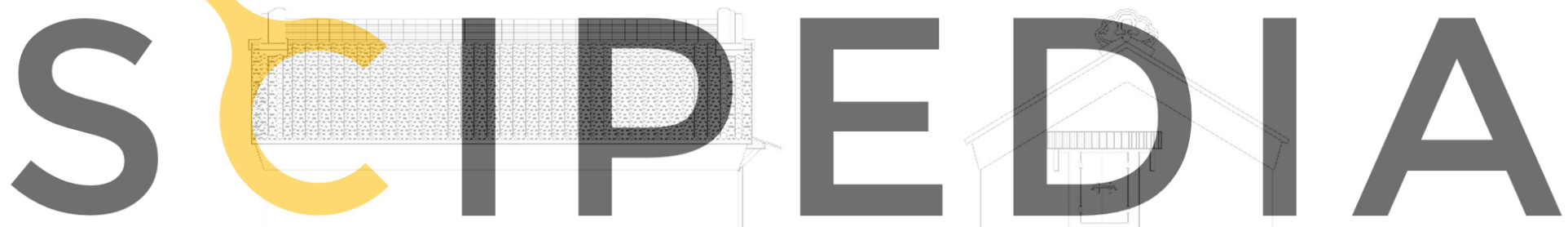

Register for free at https//www.scipedia.com to download the version without the watermark

Figure 11: Elevation view of the target building

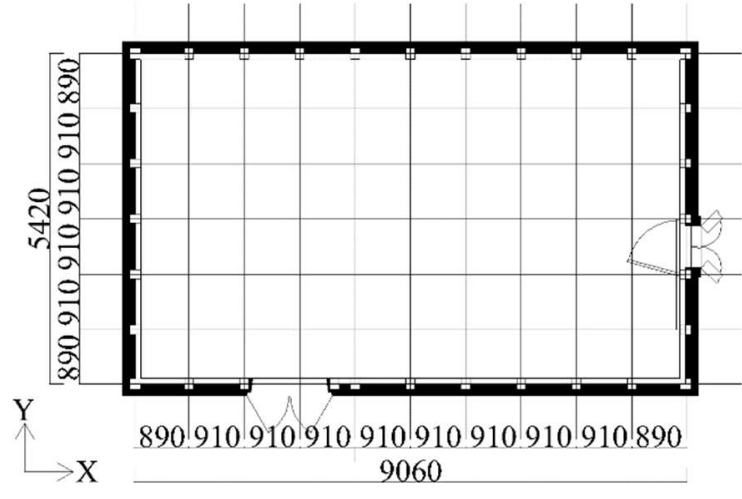

(a) 1 st floor

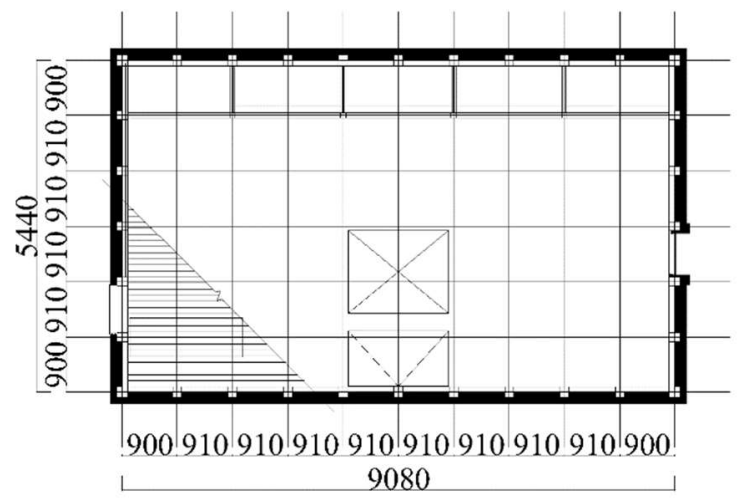

(b) 2nd floor

Figure 12: Plan view of the target building 


\section{CASE STUDY ON THE SEISMIC PERFORMANCE OF THE EXISTING BUILDING}

\subsection{Target building overview}

The building is a two-story dozo structure located in a city in Tochigi Prefecture. It has 10 spans in the $\mathrm{X}$ direction and six spans in the $\mathrm{Y}$ direction and was constructed more than 150 years ago. Figures 11-12 show the elevation and plan views of the building used as a case study model, respectively. The building weight was evaluated using the weight per unit area shown in Table 5. The weight of the first story is $279.1 \mathrm{kN}$, while that of the second story is $167.2 \mathrm{kN}$.

Table 5: Weight per unit area for the building weight evaluation

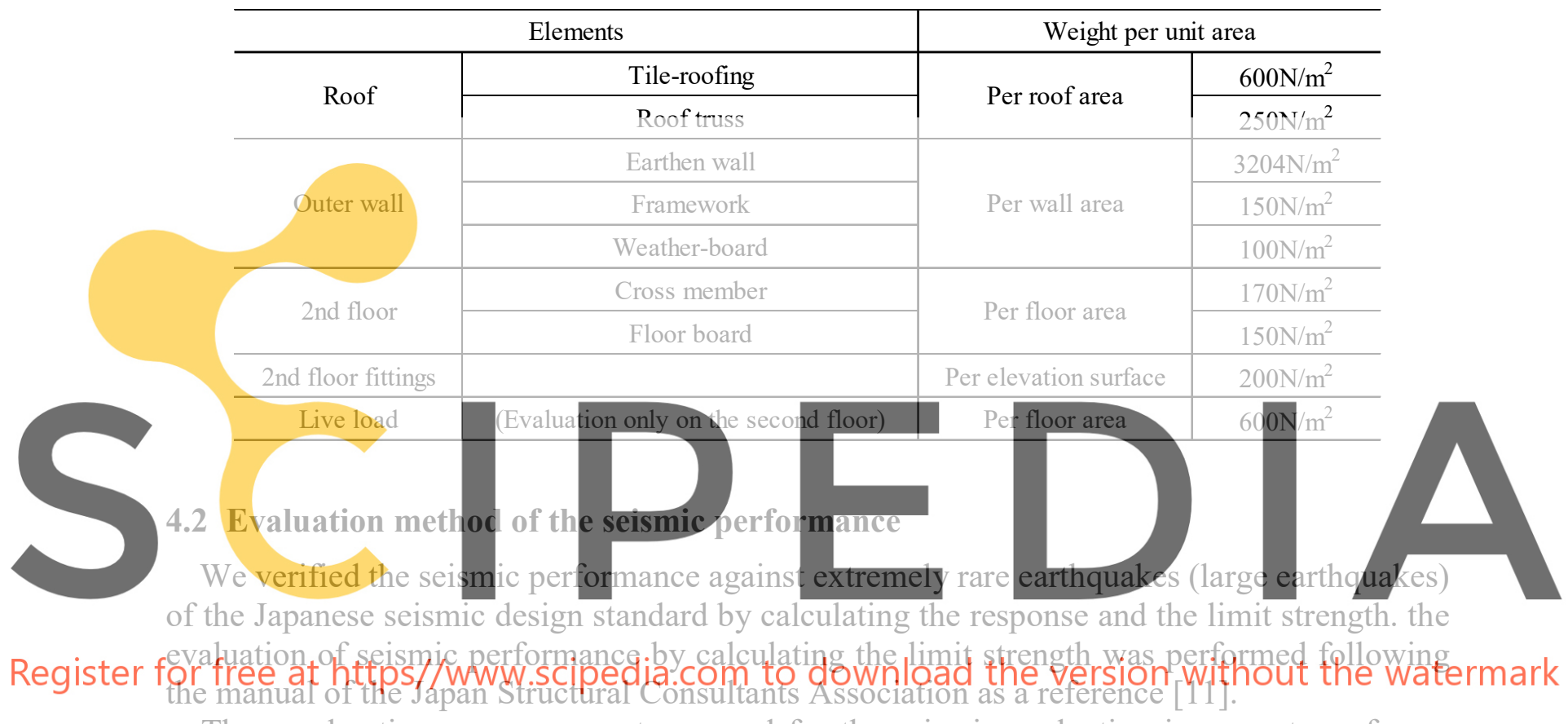

The acceleration response spectrum used for the seismic evaluation is a spectrum for an extremely rare earthquake defined in the Japanese seismic design standard. Here, the ground surface amplification was evaluated according to the simplified method of the Japanese seismic

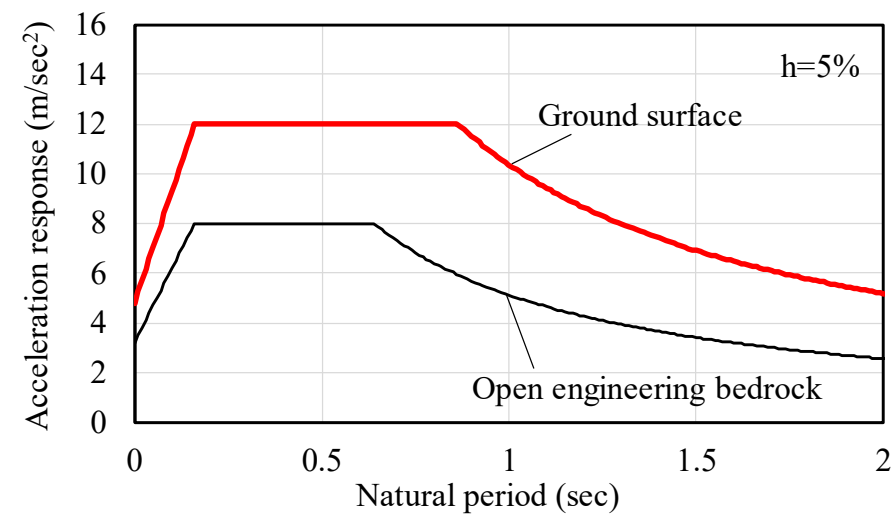

Figure 13: Acceleration response spectra $(h=5 \%)$ 
design standard. Figure 13 shows the acceleration response spectra $(\mathrm{h}=5 \%)$ at the open engineering bedrock and the ground surface amplification.

All the horizontal strength resistance elements must be added to accurately evaluate the restoring strength characteristics of a building. Examples of the horizontal strength resistance element of the target building included the earthen and hanging walls and bearing of penetrating beam and timber connection, among others. However, the contribution of the strength of the full surface earthen walls arranged to surround the outer periphery of the building was very dominant; hence, the restoring strength characteristic of the building was simply evaluated herein considering only the full surface walls. Figure 10 shows the skeleton curve used for the calculation in comparison with the horizontal loading test results. The restoring strength characteristic of the target building was evaluated by multiplying the horizontal strength per unit length, which was calculated by dividing the horizontal strength of the test result by the specimen width of $1.82 \mathrm{~m}$, by the wall length for each floor and direction. Figure 14 illustrates the restoring strength characteristics of each story and the equivalent single degree of freedom (SDOF) model in each direction. The base shear coefficients at the maximum proof strength were 0.75 and 0.46 in the $\mathrm{X}$ and $\mathrm{Y}$ directions, respectively.
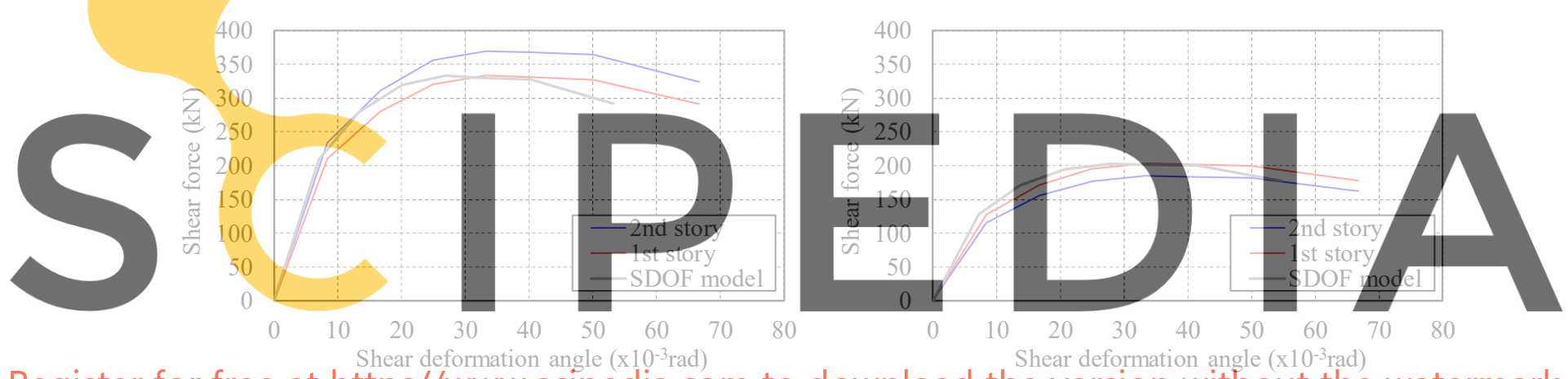

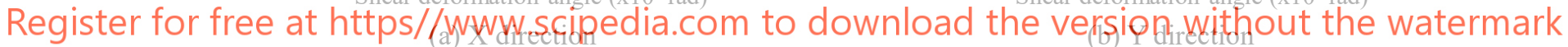

Figure 14: Restoring force characteristics

\subsection{Seismic performance evaluation results}

Figure 15 shows the structural characteristic curves (Sa-Sd spectra) of the SDOF model. Table 6 presents the maximum response deformation angle and the base shear coefficient at that deformation. The maximum response deformation angles of the first story (i.e., 1/42 rad in the $\mathrm{X}$ direction) were larger than those of the second story (i.e., 1/21 rad in the $\mathrm{Y}$ direction) in each direction. The base shear coefficients at that deformation were 0.71 and 0.45 in the $\mathrm{X}$ and Y directions, respectively.

Traditional timber frame structures in Japan can often be judged to have sufficient deformation capacity up to the story deformation angle of approximately $1 / 15 \mathrm{rad}$. In addition, the earthen wall performance confirmed in the test was observed at a certain strength level even at a large deformation of $1 / 15 \mathrm{rad}$ or more without brittle fracture. Furthermore, the planar shape of the target building was rectangular, and the torsional vibration influence was small. Considering these things, if the maximum response deformation angle is similar to that in the 
calculation results or less, then the possibility of a building collapse due to the assumed ground motion is low. However, the response deformation exceeds the maximum proof strength, and seismic reinforcement is deemed desirable for controlling the response deformation when emphasizing restorability and continuity of use.

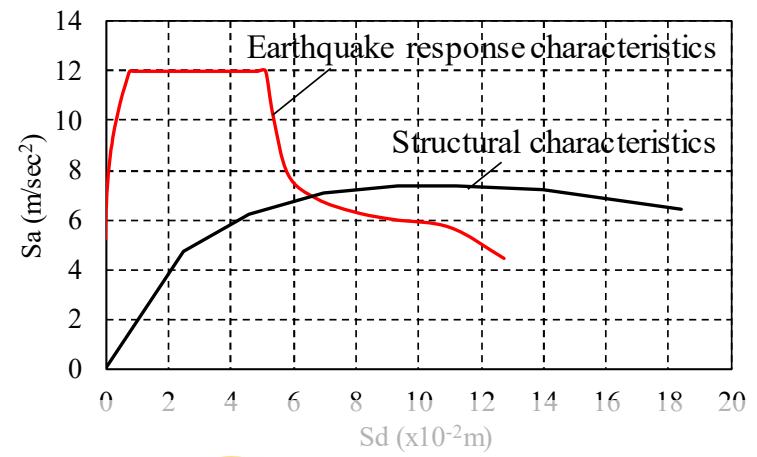

(a) X direction

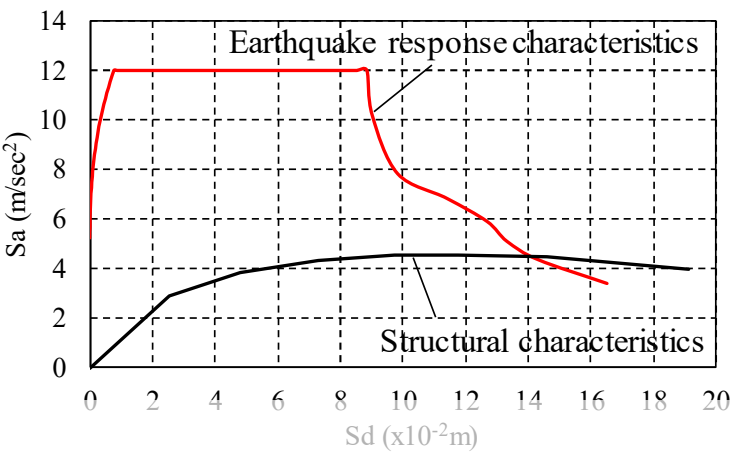

(b) Y direction

Figure 15: Structural characteristic curves (Sa-Sd spectra) of the SDOF model

Table 6: Maximum response deformation angle

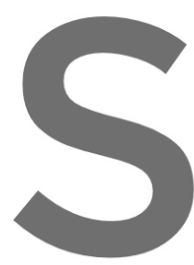

5 CONCLUSIONS
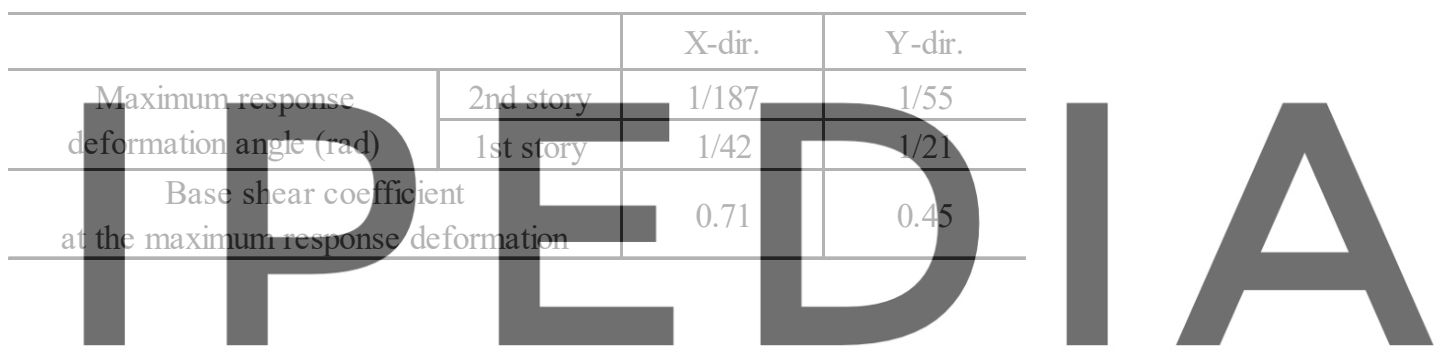

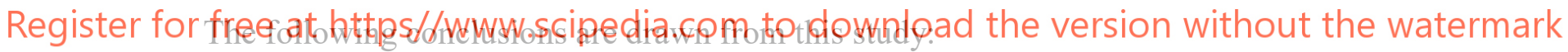

We performed a horizontal loading test on full-scale walls produced based on the survey results and the specifications of the earthen walls around the northern Kanto region to determine the walls' structural performance when receiving a horizontal force, such as an earthquake. The maximum proof strength of an earthen wall was $37.1 \mathrm{KN}$. The deformation angle at that time was $1 / 30 \mathrm{rad}$. We confirmed the toughness of the thick earthen walls through maintaining a proof strength of $84 \%$ or higher of the maximum up to the final deformation by balancing the mud wall panel resistance and the penetrating tie beams resistance.

- We conducted a case study on the seismic performance of the existing building using full-scale wall test results. The maximum response deformation angles of the first story (i.e., $1 / 42 \mathrm{rad}$ in the $\mathrm{X}$ direction) were larger than those of the second story (i.e., $1 / 21$ rad in the $\mathrm{Y}$ direction) in each direction. According to the case study results, if the maximum response deformation angle is similar to that in the calculation result or less, then the possibility of a building collapse due to the assumed ground motion is low.

- Methods of mixing soil with organic fibers (e.g., straw) and fixing soil on a substrate knitted with bamboo or wood similar to a Japanese dozo structure are used for 
construction worldwide. This study will be useful not only for Japanese dozo structures, but also for the seismic evaluation of similar buildings outside Japan.

\section{REFERENCES}

[1] E. Fodde. Traditional earthen building techniques in Central Asia. International Journal of Architectural Heritage, Vol. 3:2, (2009), pp. 145-168.

[2] Natalie Quinn, Dina D'Ayala \& Thierry Descamps. Structural characterization and numerical modeling of historic quincha walls. International Journal of Architectural Heritage, Vol. 10:2-3, (2016), pp. 300-331.

[3] M. Blondet, J. Vargas-Neumann, N. Tarque, J. Soto, C. Sosa \& J. Sarmiento. Seismic protection of earthen vernacular and historical constructions. Proceedings of the 10th International Conference on Structural Analysis of Historical Constructions, Leuven, Belgium, (2016), pp. 3-14.

[4] M. Maheri, A. Maheri, S. Pourfallah, R. Azarm \& A. Hadjipour. Improving the durability of straw-reinforced clay plaster cladding for earthen buildings. International Journal of Architectural Heritage, Vol. 5:3, (2011), pp. 349-366.

[5] Q. Ali, N. Ahmad, M. Ashraf, M. Rashid \& T. Schacher. Shake table tests on single-story Dhajji Dewari traditional buildings. International Journal of Architectural Heritage, Vol.11:7, (2017), pp. 1046-1059.

[6] C. Kawashima. Design of private houses, Overseas version (in Japanese). Suiyosha Publishing Inc. (2016), pp. 67-96.

[7] K. Ohta. Wooden building in Eastern Europe (in Japanese). Sagami-Syobo (1988), pp. 3948.

[8] H. Yokouchi, Y. Ohashi. Earthquake resistance evaluations and seismic damage assessment of Japanese traditional building in Tochigi. Proceedings of the 15th World Conference on Earthquake Engineering, Lisbon, Portugal, (2012), No. 1272.

[9] Joint Editorial Committee for the Report on the Great East Japan Earthquake Disaster. Report on the Great East Japan Earthquake Disaster (in Japanese). Building Series Volume 4, Damage of Historic Buildings, Architectural Institute of Japan (2015).

[10] National Institute for Land and Infrastructure Management. Technical manual on the shear wall factor of mud wall, surface lattice wall and inserted wooden siding wall (in Japanese). Japanese Housing and Wood Technology Center (2004), pp. 144-147.

[11] Kansai Office of Japan Structural Consultants Association. Seismic performance evaluation and seismic retrofitting manual for wooden house and building mainly using traditional timber frame construction (in Japanese), Second Edition (2014). 